\title{
SOHO returns, Mars Surveyor hiccups
}

[WASHINGTON] Ground controllers regained command of the errant Solar and Heliospheric Observatory (SOHO) last week for the first time in almost three months. Their achievement has raised hopes that scientific use of the European-US satellite could resume within the next two months.

After weeks of slowly thawing fuel lines connected to SOHO's onboard thrusters, a team of European and US engineers working at NASA's Goddard Space Flight Center in Maryland successfully commanded the spacecraft to point its onboard solar power arrays toward the sun on 16-20 September.

Next will begin check-outs of key engineering subsystems and SOHO's 12 scientific instruments, which suffered extreme heat and cold during the period in which the spacecraft was uncontrolled. Mario Acuña, project scientist for the International SolarTerrestrial Physics programme at Goddard, says that temperatures on some instruments went beyond the range that onboard sensors could record.

Still, he says, "the mood is one of optimism" that SOHO will resume scientific observations. If all the instruments work properly, that could happen in as little as four to six weeks, according to project engineers.

An accident investigation board determined earlier this month that the loss of $\mathrm{SOHO}$ in June was due to mistakes made by ground controllers, including an erroneous decision that disabled part of the spacecraft's autonomous failure detection system. Ironically, the day after SOHO was recovered, the Mars Global Surveyor (MGS) currently in orbit around Mars experienced its own brief shutdown caused by a faulty computer instruction sent up from the ground.

Engineers at NASA's Jet Propulsion Laboratory had been preparing for a propulsive manoeuvre to begin lowering the Surveyor's orbit around the planet when a bad software command turned the craft's solar power panels at the wrong angle to the sun. That made onboard batteries start draining power. In this case, however, the spacecraft's automatic fault protection system caught the mistake and aborted the manoeuvre when power fell below 50 per cent.

The fact that a faulty software command survived several levels of review on the ground before being transmitted to the

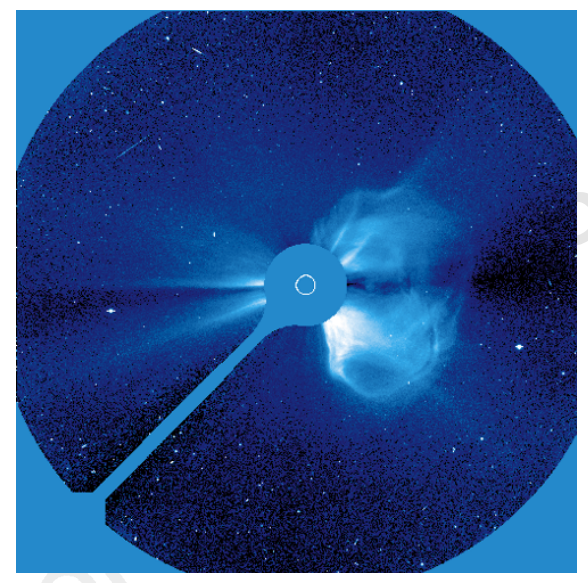

Former glory: SOHO's view of a coronal mass ejection from the Sun last April.

spacecraft is "a little disconcerting", admits MGS project manager Glenn Cunningham. But - unlike SOHO — the MGS's fault protection system saved the day. "It did exactly what it was supposed to do," says Cunningham. As a result, the Mars spacecraft is safe and stable, and is due to resume lowering its orbit as planned this week. Tony Reichhardt

\section{Call for scientific experts to keep State Department up to speed}

[WASHINGTON] A dozen well placed technical staff and a \$500,000-a-year external advisory board could revive the scientific and technical capabilities of the US Department of State. So says a preliminary report prepared by the National Academy of Sciences and delivered earlier this month to Madeleine Albright, the secretary of state. Important issues on science and technology "are not receiving adequate attention within the department", says the report. It was written over the summer by a panel chaired by Robert Frosch of Harvard University's John F. Kennedy School of Government in response to mounting criticism of how the state department handles science-related issues.

Briefing a meeting of the President's Council of Advisors on Science and Technology on the study last week, Frosch said there were plenty of sources of sound advice on science and technology available in Washington, but that the state department was ill-equipped to access it.

"The question is how the state department can develop better internal receptors" for scientific input, Frosch said. "We suggest that the secretary of state asks one of the under-secretaries to take special responsibility for these issues."

Scientists in the United States have long complained that the state department, which is responsible for US foreign affairs, is ill-equipped to handle scientific and technical questions. But the complaints have sharpened markedly over the past year (see Nature 392, 427; 1998).

Critics charge that, under the Clinton administration, the state department's Office of Oceans and International Environmental and Scientific Affairs (OES) has concentrated on the environment at the expense of science.

They also claim that the department's meagre scientific and technical capability is overwhelmed by the range of foreign-policy issues - from international copyright laws to trade disputes involving satellites or genetically modified organisms - which now revolve around science or technology.

The Frosch study says that the state department should hire two or three technical staff in the office of the undersecretary who would be assigned special responsibility for science and technology. It should also develop "several additional clusters" of scientific competence at five of its other Washington bureaux.

The report adds that the department should set up procedures enabling it to second people from science agencies, such as the National Science Foundation, to fill science counsellor positions at US embassies with suitably qualified staff. It suggests an array of possible mechanisms to garner advice on science and technology.
The most comprehensive of these would be a formal advisory committee modelled on the Defense Science Board, which advises the Pentagon.

The panel was hesitant in recommending the appointment of a science advisor to the secretary. Glenn Schweitzer, the study director, notes that interest groups such as women and labour unions have pressed for similar appointments to represent their particular interests. "We're reluctant to line up with them just yet," Schweitzer says.

The department is recruiting a science adviser for Melinda Kimble, the assistant secretary for OES (see Nature 393, 612; 1998). But Frosch says this will have little effect on the department as a whole.

The interim Frosch report was produced quickly to help the state department prepare its budget for 2000. In a letter to Albright, Bruce Alberts, the president of the National Academy of Sciences, said the report's recommendations could be implemented with the establishment of about 12 positions and, at most, $\$ 500,000$ for the advisory structure. "These seem modest investments given the stakes involved," Alberts wrote.

Alberts also asked for a meeting with Albright to help direct a fuller report from the Frosch panel, due in a year's time. Although she requested the study, the most senior official to meet the Frosch panel was her deputy, Strobe Talbot. Colin Macilwain 